\title{
Subliminal practice effects in verbal learning'
}

TOSH HAYASHI

UNIVERSITY OF WATERLOO

\begin{abstract}
A list of paired-associates, in which the response member of each pair was subliminal, was presented to each of 12 male Ss. Half of the response stimuli consisted of taboo words. The Ss were then given supraliminal presentations to a criterion of one errorless trial on a list essentially the same as the subliminal list-except that the taboo words had been replaced by neutral words. Performance was significantly better on the paired-associates that remained unchanged from subliminal to supraliminal presentation. This was interpreted as a subliminal practice effect.

Problem
\end{abstract}

A recent study by Vernon \& Badger (1959) failed to demonstrate subliminal practice effects on a verbal learning task. The present study was designed to investigate the same problem. The two studies therefore warrant comparison with respect to methodology.

In the Vernon and Badger study, comparisons were made across different treatment groups of Ss; the subliminal practice session was given by means of a tachistoscope while the supraliminal learning task was presented on a memory drum; subliminal was defined as the $25 \%$ limen of recognition for each S; and paired neutral adjectives served as the paired-associates. The present study differs on all these points:

Comparisons were made within Ss. Both subliminal and supraliminal sessions were given tachistoscopically. By keeping conditions constant throughout the experiment it was hoped that the S's set would remain uniform from the subliminal to the supraliminal session. Subliminal was defined as "below" the zero\% recognition limen for each $\mathrm{S}$, in actual practice very near the limen of detection. Taboo as well as neutral words were used. Since taboo words have much greater affective significance than neutral words-as even a "response-bias" theorist would admit (Bevan, 1964) -it remains a plausible assumption that the taboo words may have the more effective properties for influencing behavior subliminally.

\section{Method}

Ss were 12 male students in their junior year at college. Ss wearing glasses were tested with them on.

A Rootnearpoint tachistoscope was used to present the response items. This had variable shutter speeds with discrete settings of $1,1 / 2,1 / 5,1 / 10,1 / 25,1 / 50$, $1 / 100$, and $1 / 400$ th of a second. The response items, in elite type and centered on 3 by 5 cards, were fed manually into the tachistoscope. Distance from eyepiece to card was 21-1/2 in.

The subliminal paired-associates consisted of six neutral stimulus items, of which half were paired with neutral and half with taboo response items. The pairing was counterbalanced in two separate lists. Call these subliminal-1 and subliminal-2. Order effects were controlled by making up three random orders for each list.

Since the stimulus items were to be presented orally by $\mathrm{E}$, the only restriction imposed here was that they had to be highly common, one syllable words. The response items were all highly common four-letter words.

The supraliminal lists were identical to the subliminal lists with two exceptions. Where there had been taboo items subliminally, there were now neutral items. Also, the length and consequently the difficulty of the supraliminal lists was increased by the addition of two extra "irrelevant" pairs of items. It was hoped the lists would be of sufficient difficulty to rule out ceiling effects in performance.

\section{Procedure}

The zero\% recognition limen was determined for each $S$ by the method of limits. Each of 10 neutral four-letter words, none of them being in any of the subliminal or supraliminal lists, was presented to the $\mathrm{S}$ in an ascending series. The fastest exposure at which $\mathrm{S}$ recognized any one of the words defined the upper limit of his zero\% recognition limen.

Half the Ss were assigned to subliminal-1 and half to subliminal-2. During the subliminal session, the stimulus member of each paired-associate was voiced by the $\mathrm{E}$ and followed $2 \mathrm{sec}$. later by three subliminal exposures of its response item. These were presented well below the zero\% recognition limen. Each list was presented in its entirety six times.

Prior to the subliminal presentations each $\mathrm{S}$ was told that with sufficient concentration the nature of the subliminal stimulus might occur to him via ESP. He was also told to report any "chance" recognition of a response item. (None that did hazard a report identified the item correctly.)

After the subliminal session, each $\mathrm{S}$ was given the supraliminal learning task. Procedure was identical to that followed during the subliminal session except that the response items were exposed at 1 sec. duration, well above threshold, and the $\mathrm{S}$ was required to learn the list of paired associates to a criterion of one errorless trial.

\section{Results and Discussion}

The important finding was that 10 of 12 Ss made fewer errors on the paired-associates that remained unchanged from subliminal to supraliminal exposure. The t-test done on the difference scores was highly 
significant $(t=4.06, d f=11, p<.01)$.

These results strongly suggest that subliminal learning had occurred. The fact that these results were positive while the Vernon \& Badger study (1959) yielded negative results suggests that the importance of the methodological differences outlined above require study.

While a subliminal practice effect could be said to have occurred, it is impossible to determine from the present study whether it was primarily a positive or a negative transfer effect. This question should be answered next. One approach to this problem would be to incorporate into the present design another group of paired-associates in which the stimulus items are paired with "blanks" during the subliminal session.

Had the words comprising the "irrelevant" pairs been selected on the same basis as the items making up the other paired-associates, an analysis of performance on these might have shed some light on the type of transfer effect that occurred in this study. Fewer errors were in fact made on these pairs than on the others. However this was most likely an artifact. The "irrelevant" pairs had purposely been made up of items having a high degree of association with one another (e.g., "cat" and "mouse") consequently it is not surprising that they would be learned more easily. Their original purpose was to "pad-out" the supraliminal lists to a length that would reduce the probability of the $\mathrm{S}$ reaching criterion on the second trial, as he well might have had there been only six paired associates. The author's prime motive in executing this study was to test the possibility that a subliminal practice effect in verbal learning could occur at all.

Another problem worth investigation concerns the relative effectiveness of neutral and taboo words in this type of paradigm. This problem also could be tackled by incorporating into the present design another group of paired-associates. For the subliminal condition, each of these pairs would have a neutral response item that would be replaced by a different neutral item on the supraliminal task.

\section{References}

Bevan, W. Subliminal stimulation: a pervasive problem for psychology. Psychol. Bull., 1964, 61, 81-99.

Vernon, J. A., \& Badger, D. H. Subliminal stimulation in human learning. Amer. J. Psychol., 1959, 72, 265-266.

\section{Notes}

1. This study was carried out at the University of Manitoba. The author thanks Dr. R. J. Koppenaal for his help in designing the study.

2. Upon request the author will supply the list of "taboo" words used in this study. 